\section{Catalog of Maps}

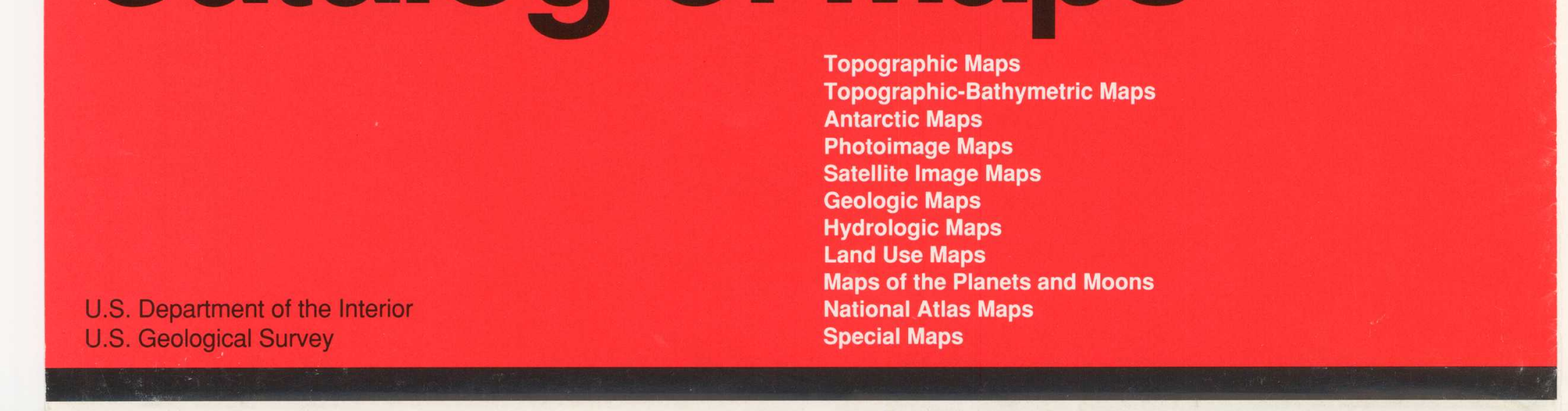

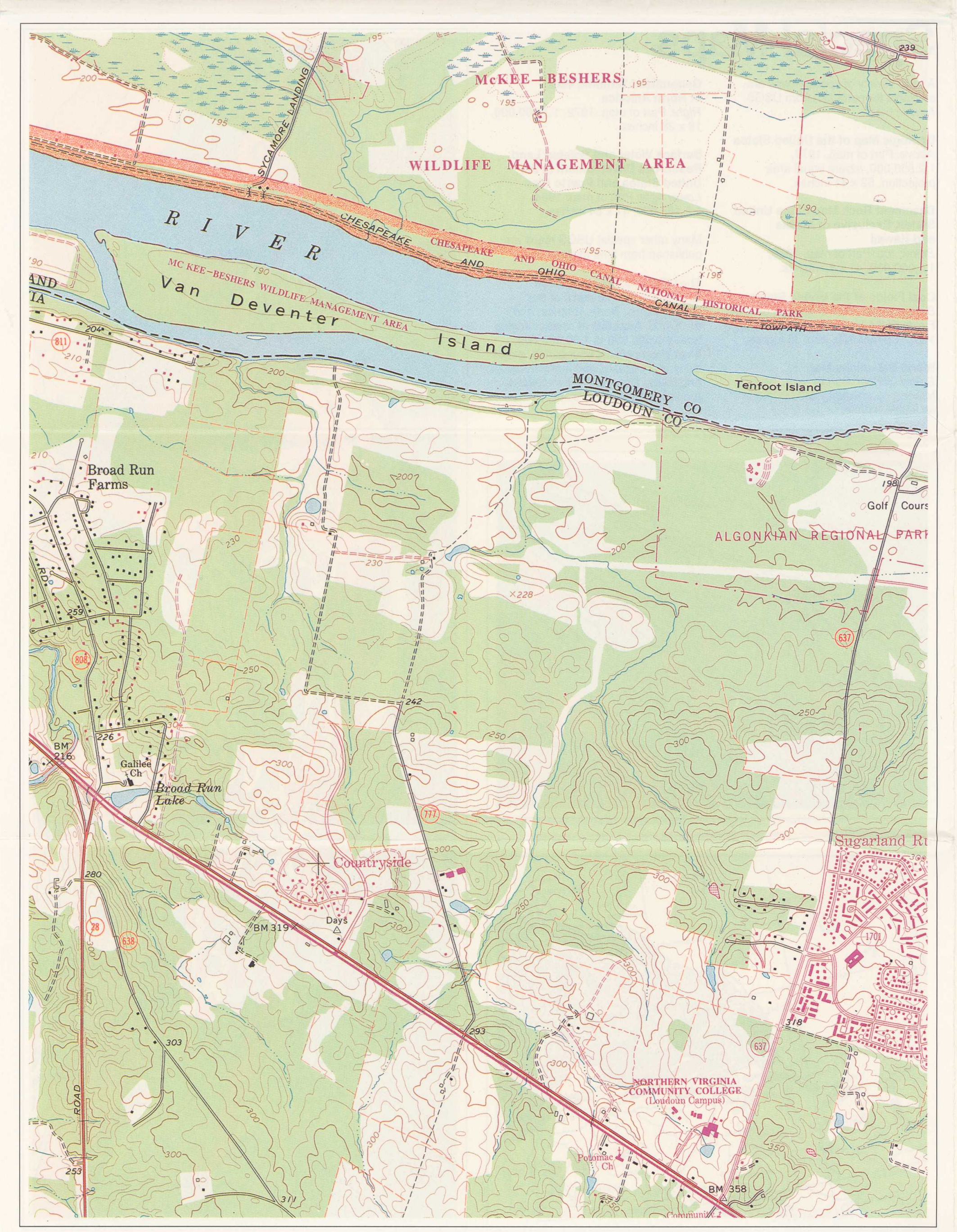

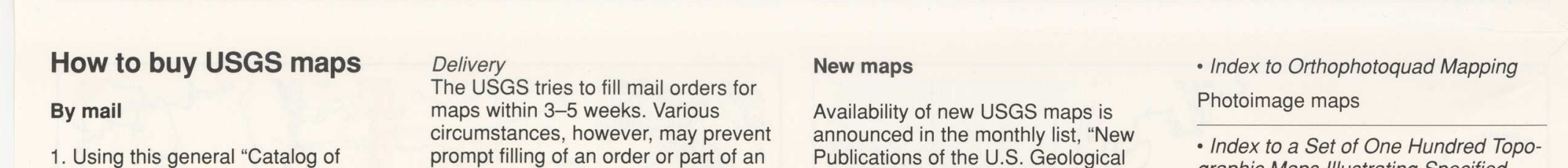

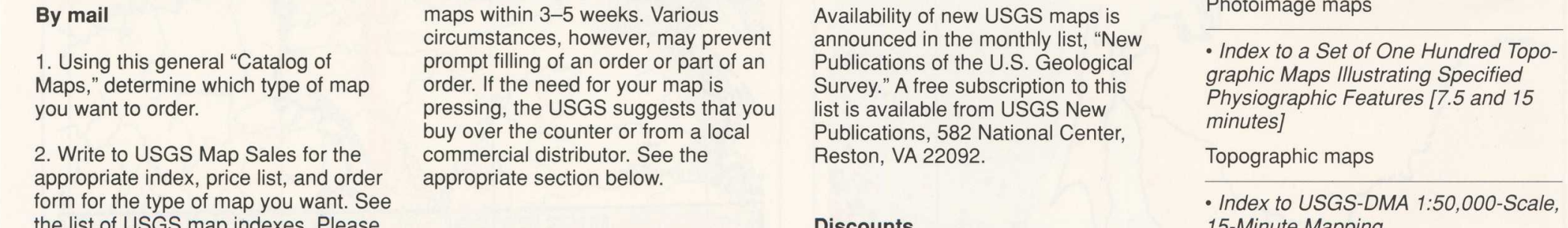

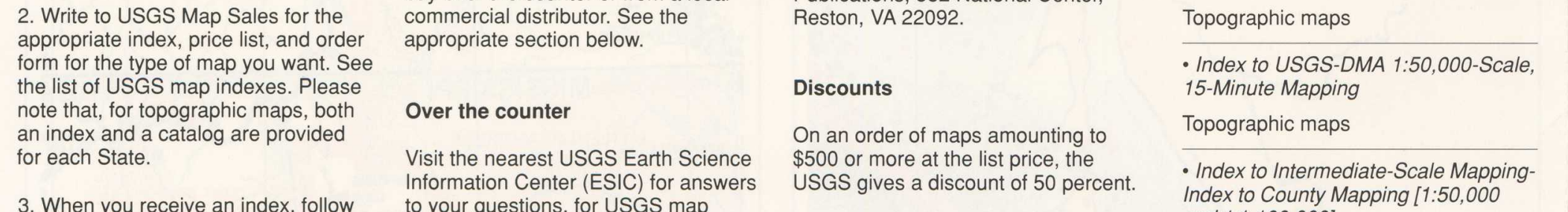

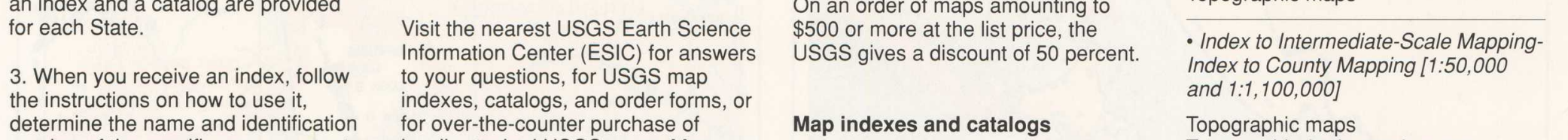

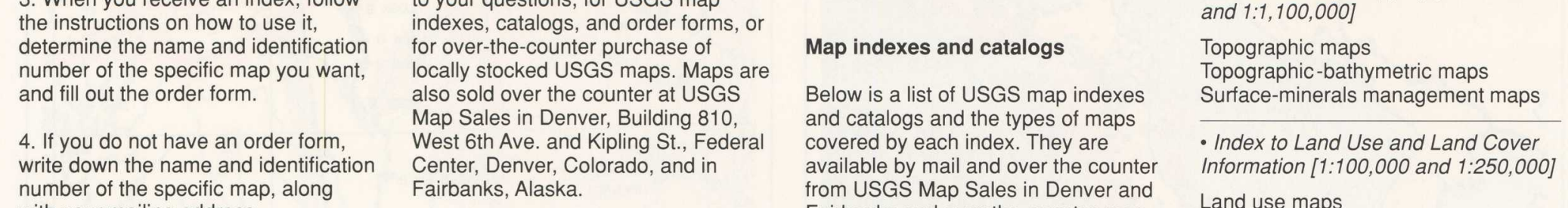

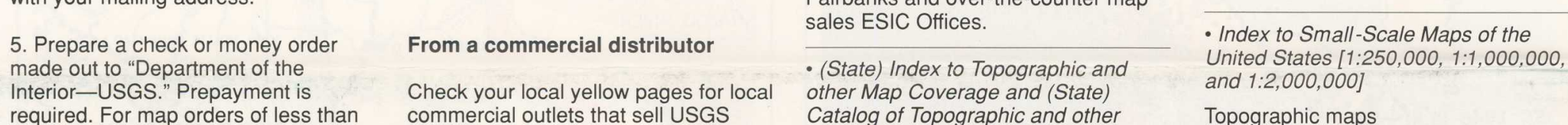

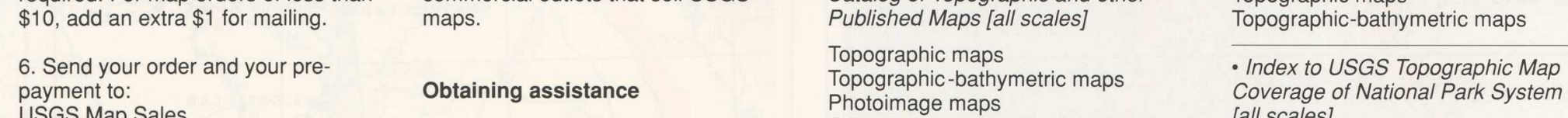

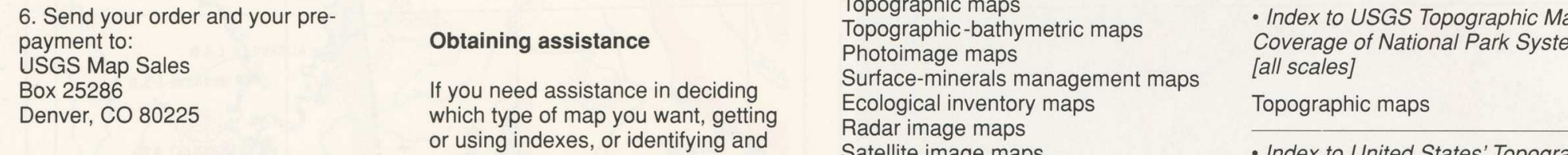

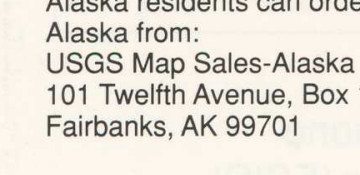

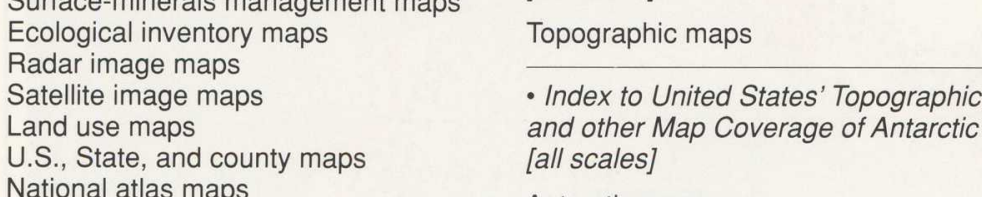

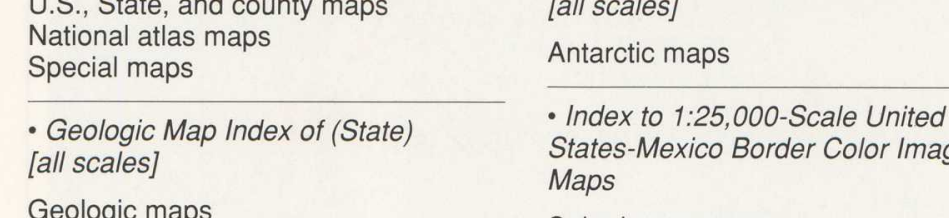

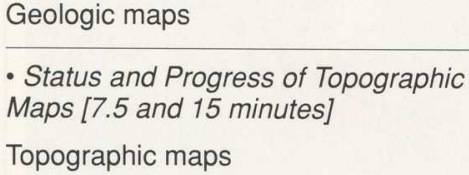

\section{Topographic Maps}

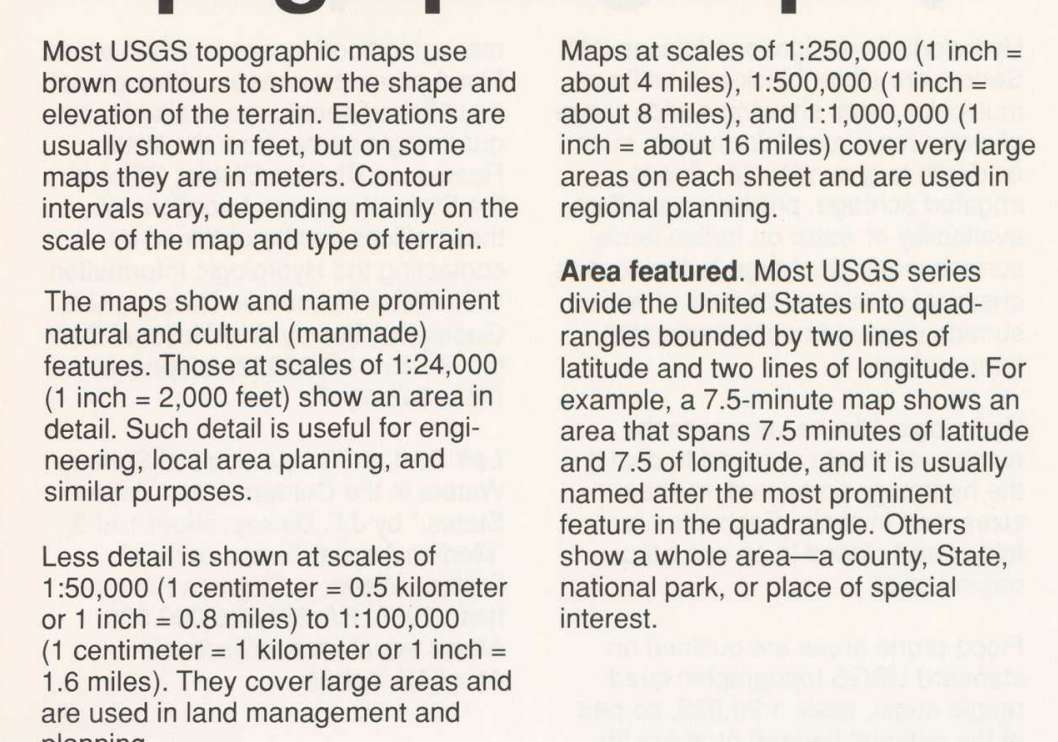

7.5.minute maps

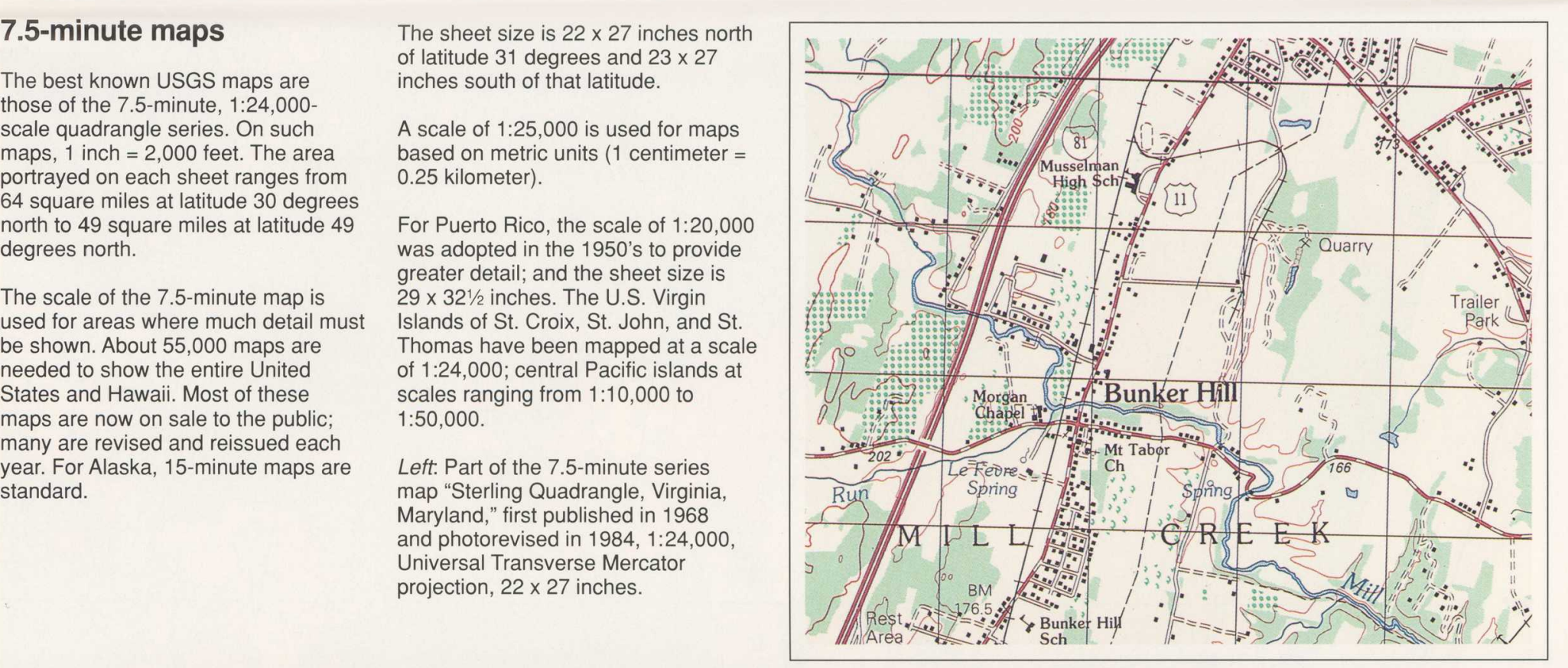

\section{(2)}

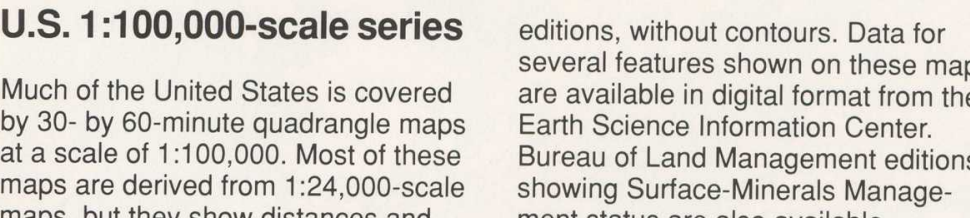

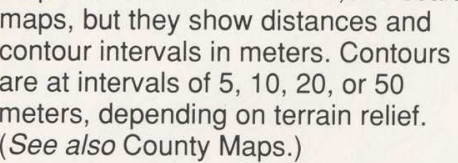

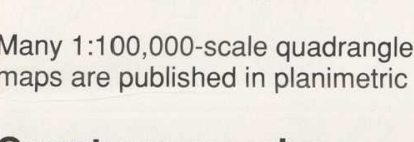

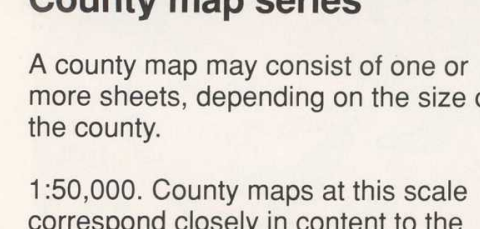

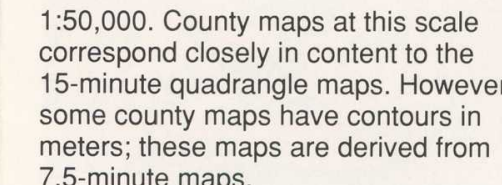

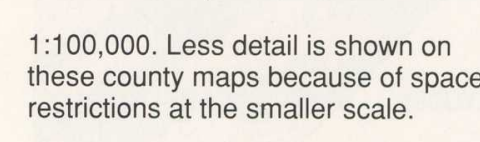

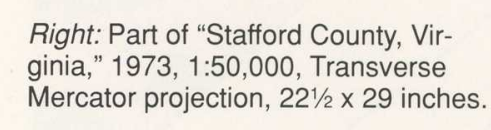
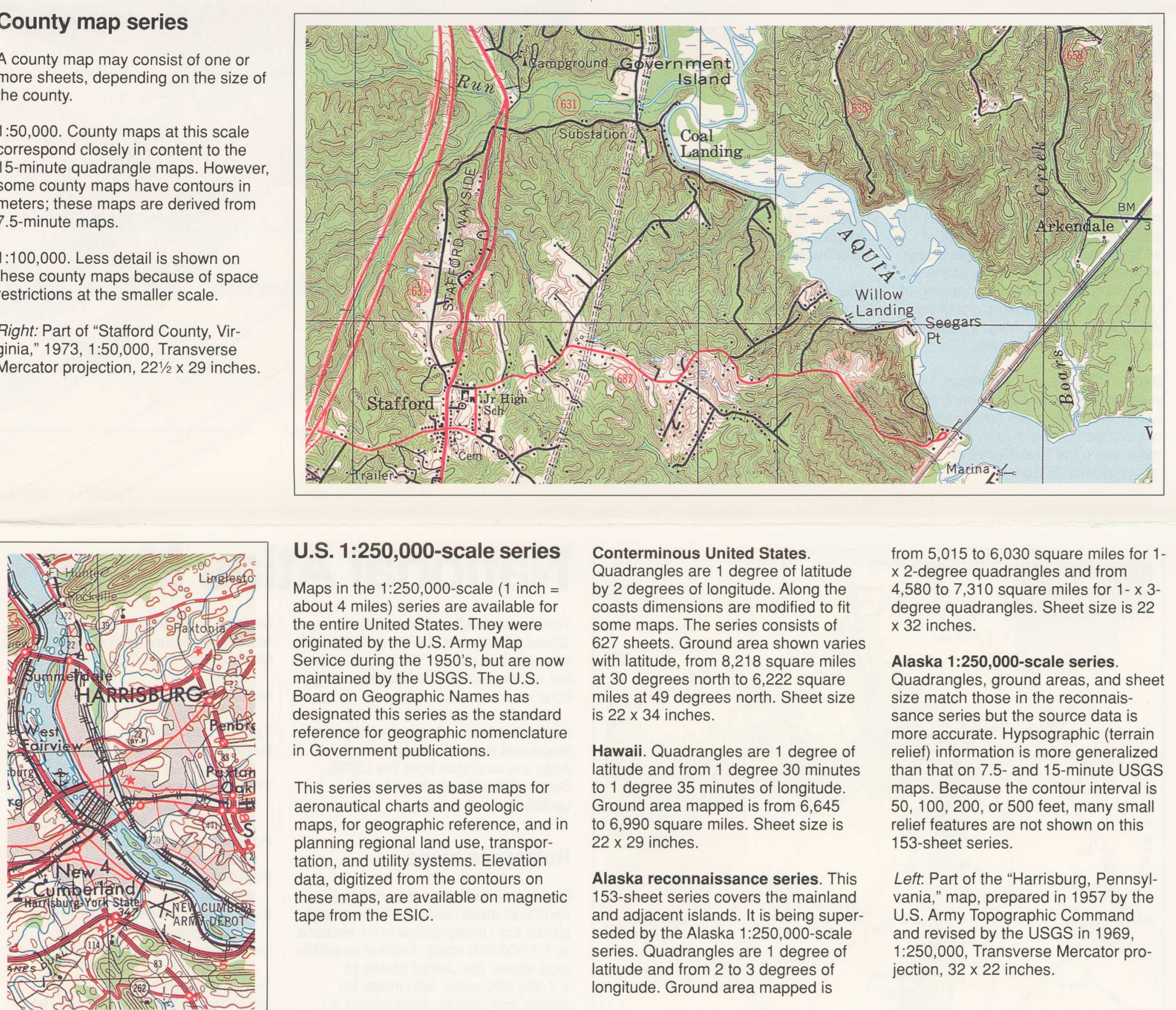

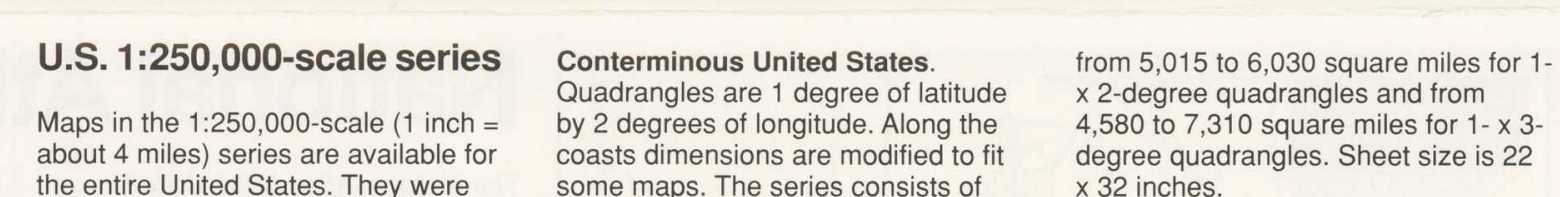
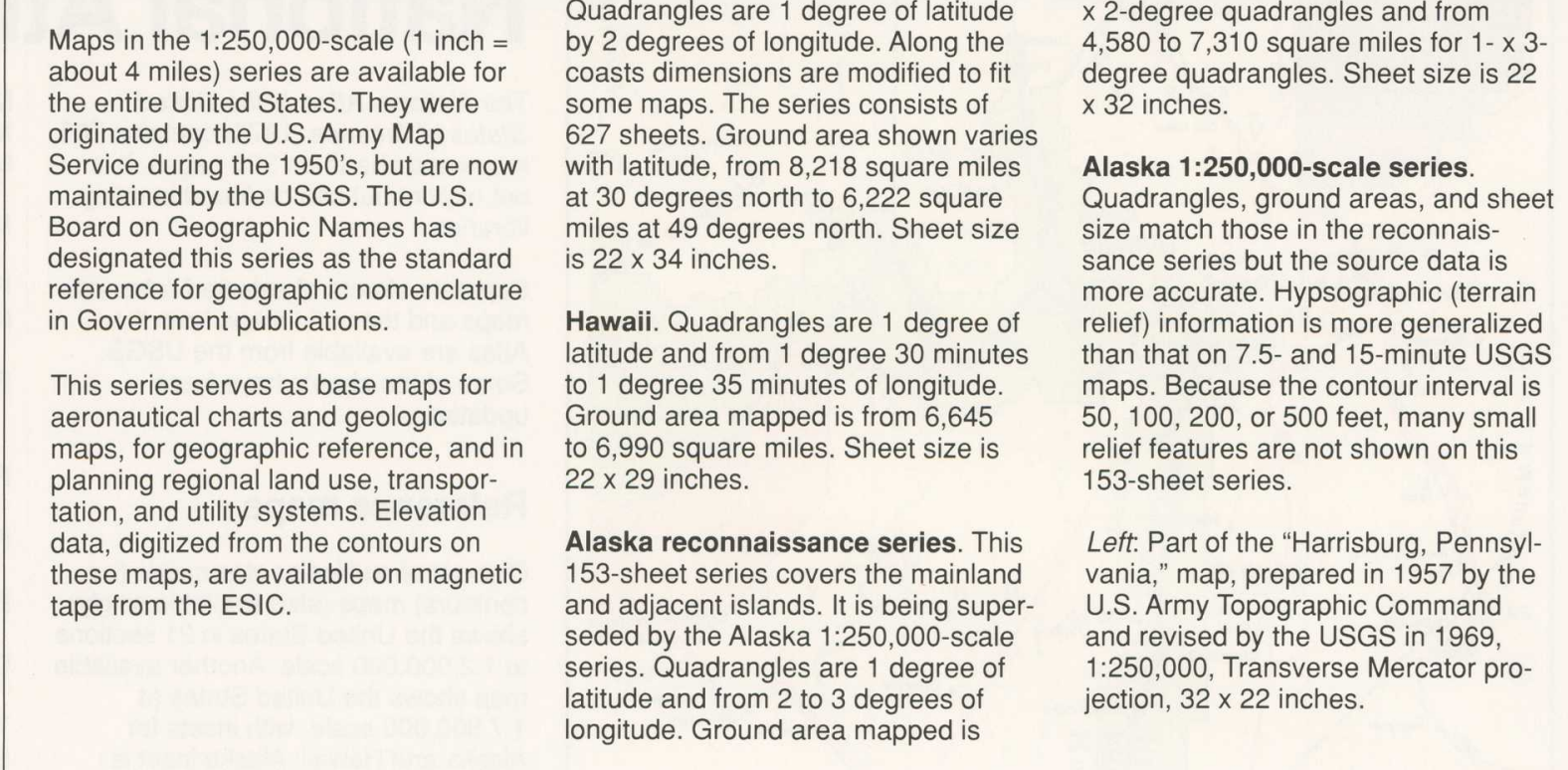

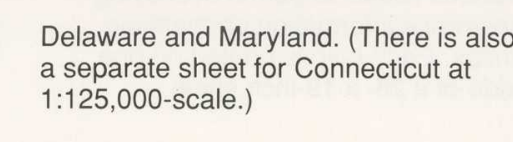

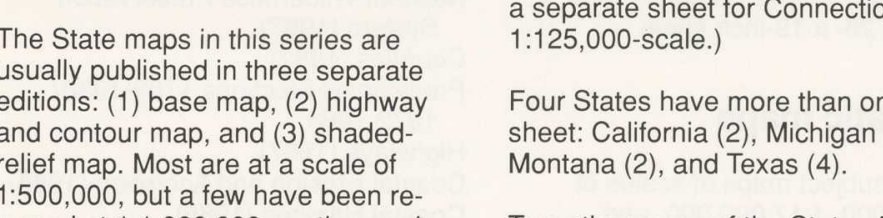

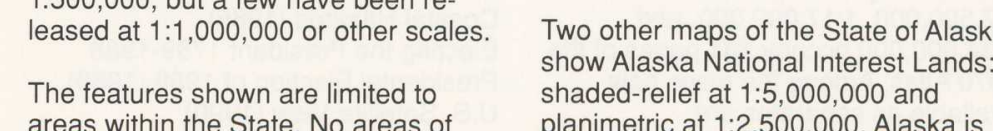

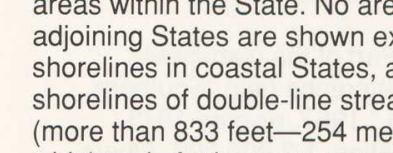

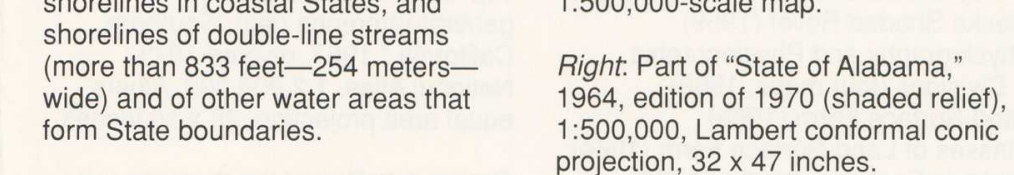

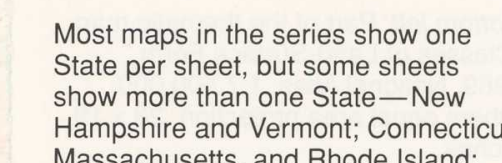
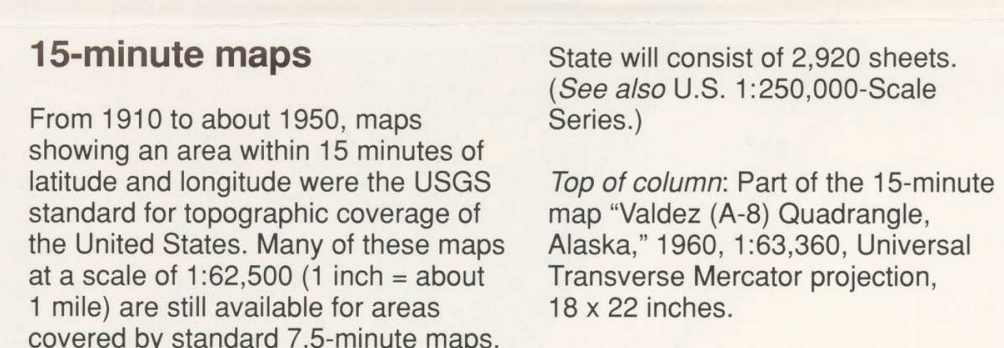

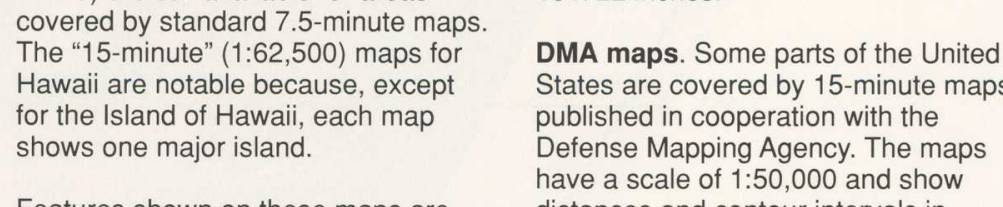

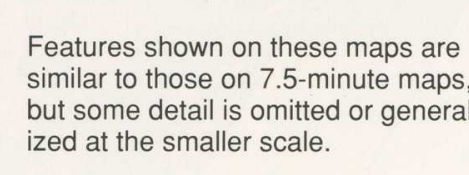

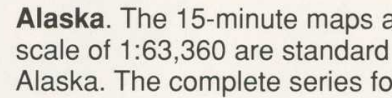
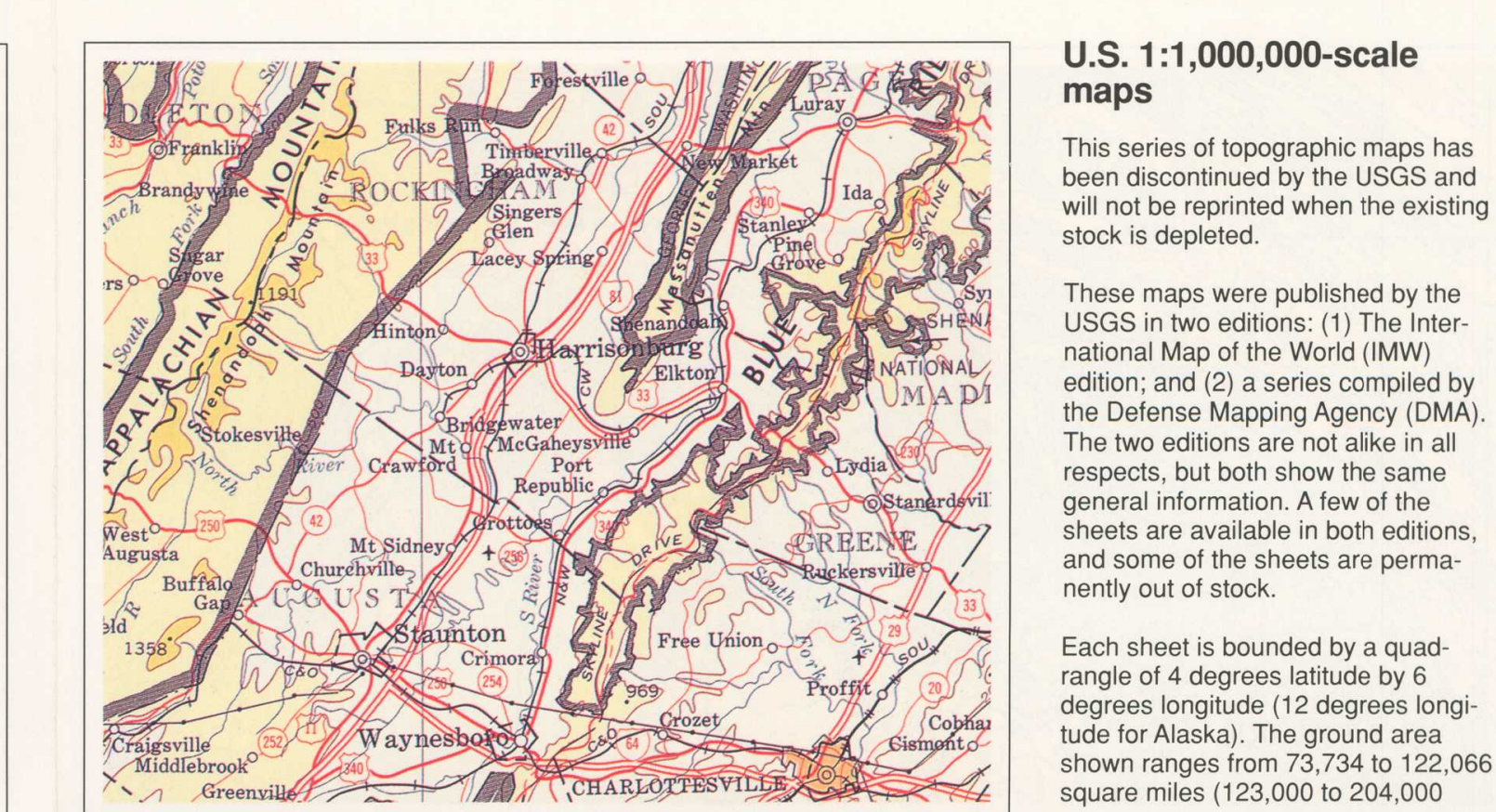

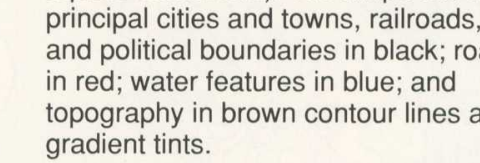

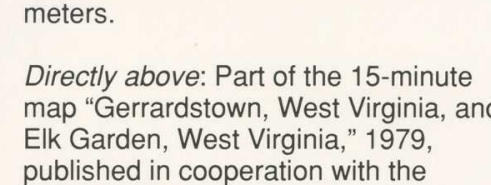

(1)
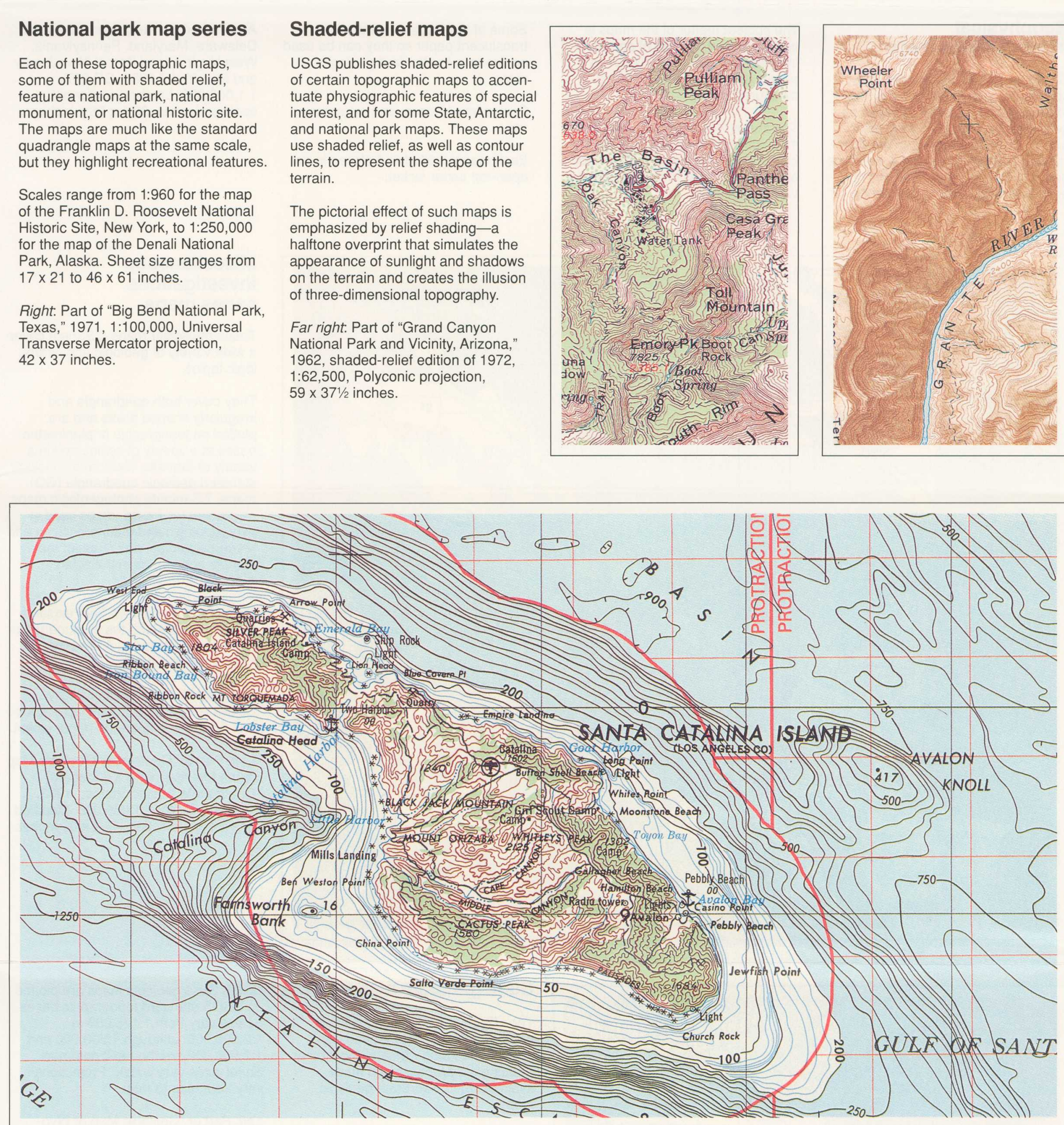

\section{Topographic-Bathymetric Maps}

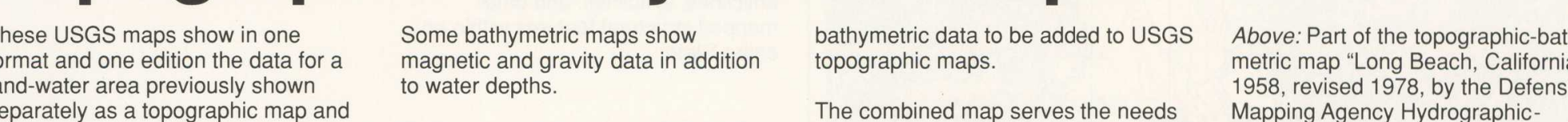

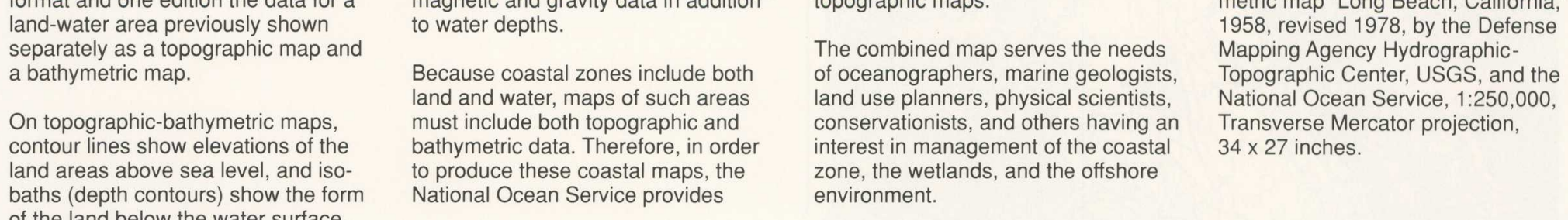

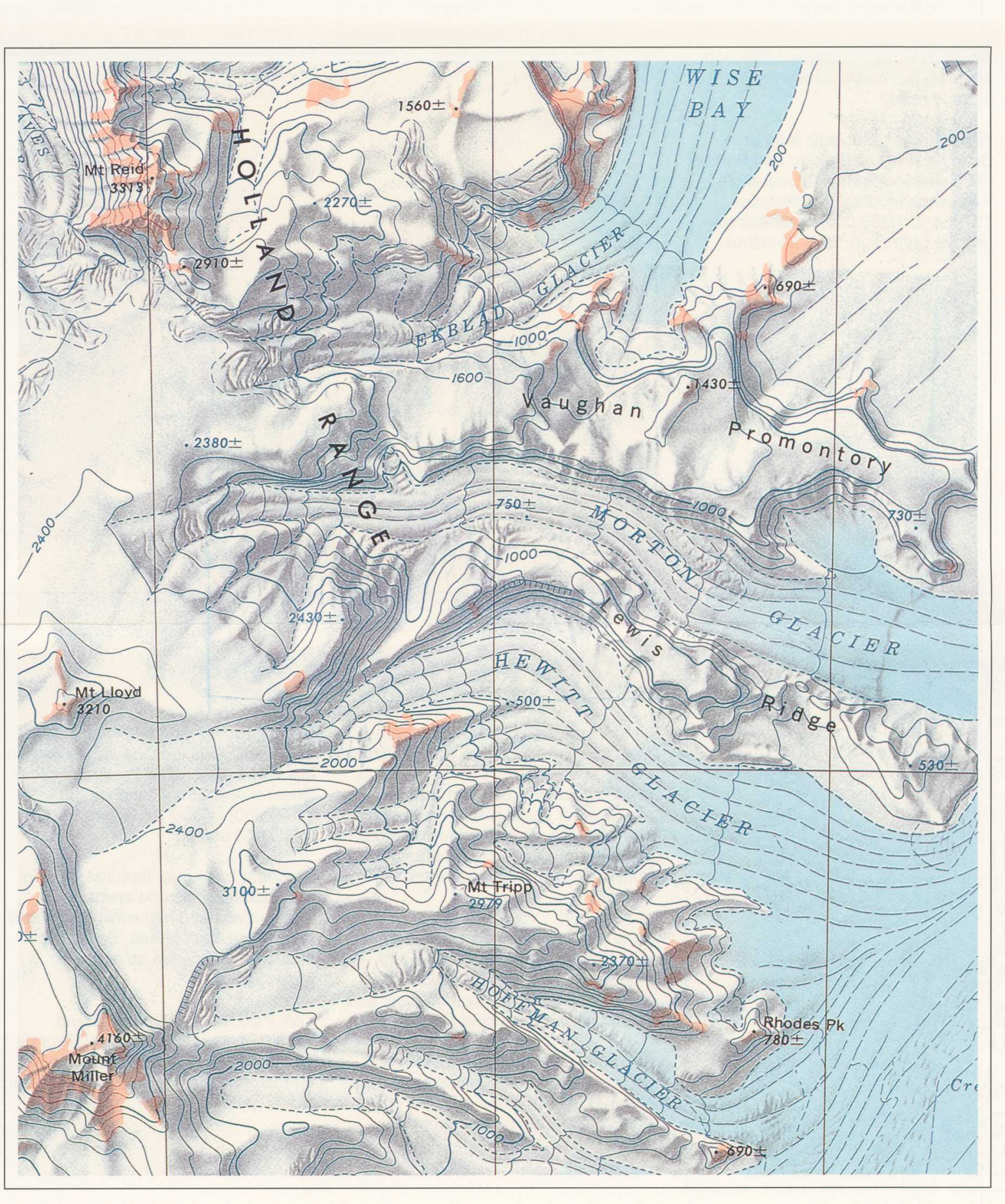

Antarctic

Maps

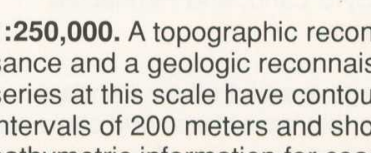

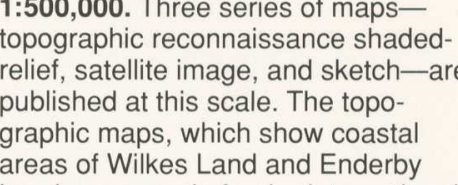

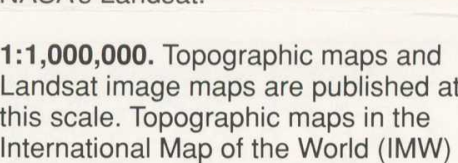

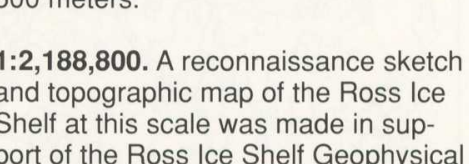

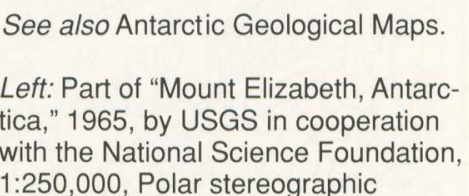

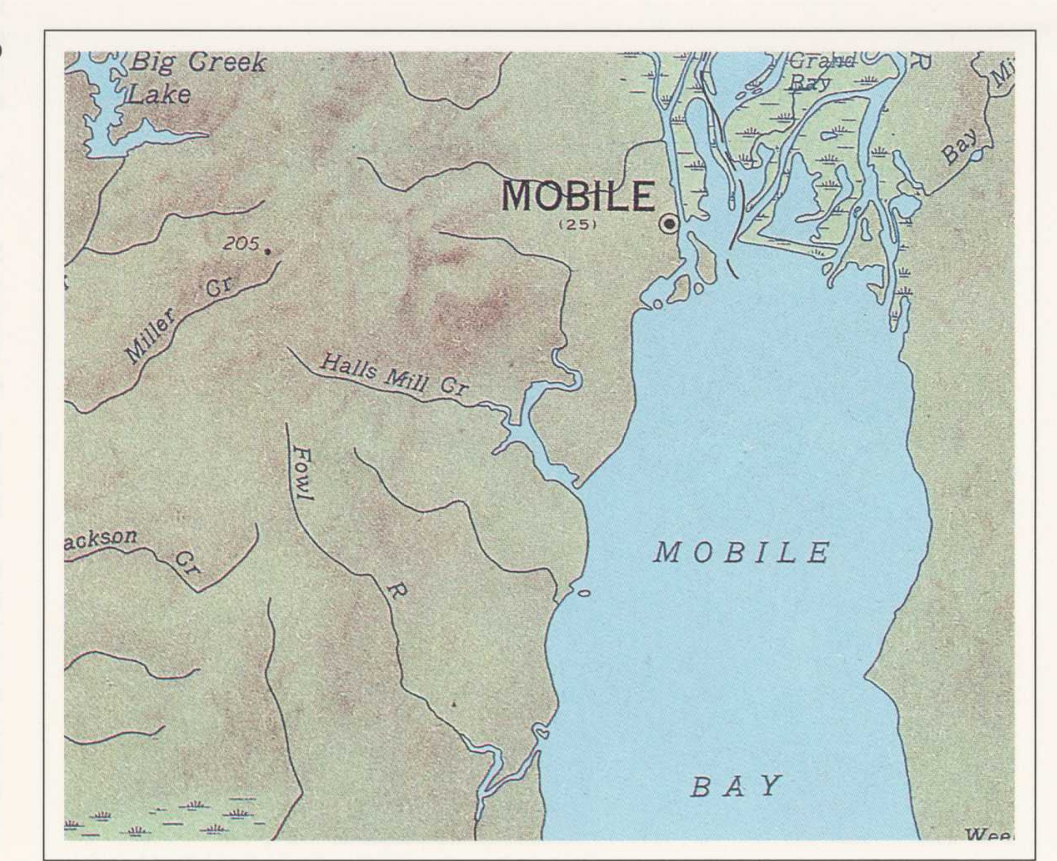

Photoimage Maps
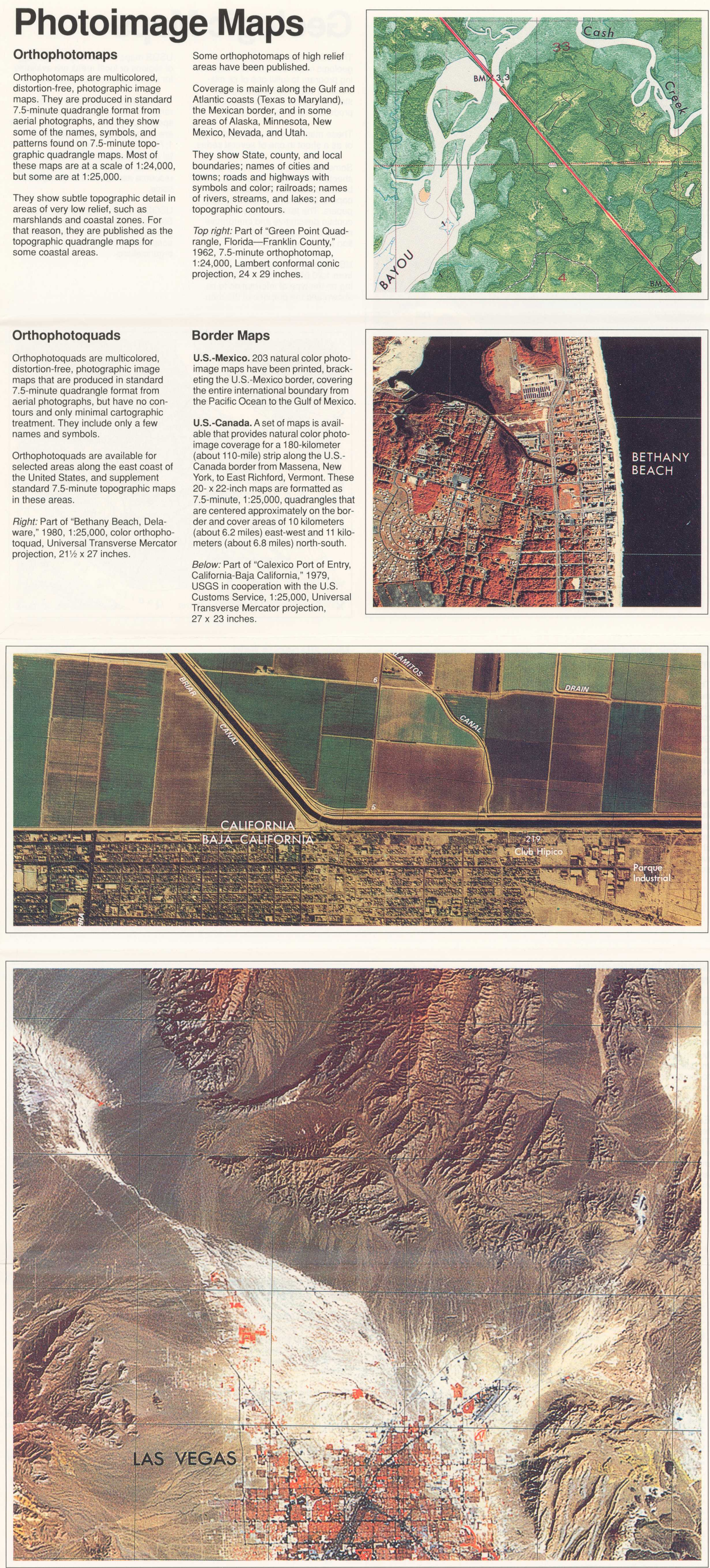

Satellite Image Maps
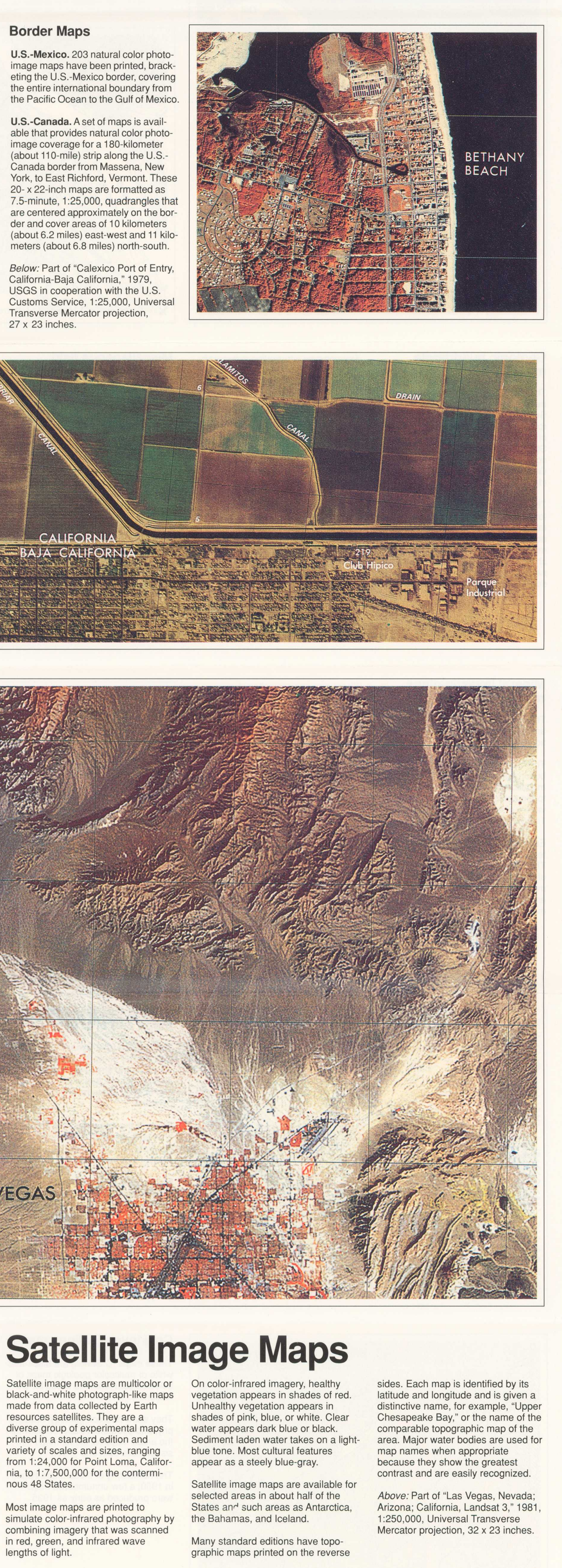